\title{
Design and Comparison of Feasible Control Systems for VSC-HVDC Transmission System
}

\author{
Boyang Shen \\ Department of Engineering \\ University of Cambridge \\ Cambridge, UK \\ bs506@cam.ac.uk
}

\author{
Sheng Wang \\ School of Engineering \\ Cardiff University \\ Cardiff, UK \\ WangS9@cf.ac.uk
}

\author{
Lin $\mathrm{Fu}$ \\ Department of Engineering \\ University of Cambridge \\ Cambridge, UK \\ lf359@cam.ac.uk
}

\author{
Jun Liang \\ School of Engineering \\ Cardiff University \\ Cardiff, UK \\ LiangJ1@cf.ac.uk
}

\begin{abstract}
This Paper presents the modeling and control of two-terminal Voltage Source Converter Based High Voltage Direct Current (VSC-HVDC) transmission system which are achieved using the software of PSCAD/EMTDC. There are two control designs for VSC-HVDC system in this project: 1. Phase and magnitude control design; 2. Control design under d-q frame. The VSC-HVDC system is operated successfully by using these two control methods respectively. Finally, this paper illustrates the analysis of steady state tests and dynamic load tests of VSC-HVDC system, as well as the comparison of the two control methods.
\end{abstract}

Keywords- HVDC; VSC; IGBT; PWM; D-Q frame; Phase and magnitude

\section{INTRODUCTION}

In the new millennium, with the increasing energy issues, the renewable energy technologies are representing a lowcost and dependable alternative to the conventional generation technologies [1,2]. Nevertheless, the renewable energy technologies introduce new challenges to the power transmission system [1-3]. The main advantages of HVDC transmission system attribute to the long distance bulk power delivery with fewer losses, as well as the interconnection of asynchronous networks [1-4].

With the development of LCC (Line Commutated Converter) technology, bulk of power was able to be transmitted by LCC-HVDC [5]. However, the controllability of the system had not been achieved and huge amount of reactive power was needed in LCC operation $[1,5,6]$. Moreover, tremendous harmonic content was presented [6, 7]. With the consistent development of high voltage and fully controlled power electronic devices, the use of VSCs (Voltage Source Converters) in high voltage applications became possible, which was established by using signal controlled power electronic devices, such as IGBT (Insulated Gate Bipolar Transistors) [6-8]. IGBT can be used for VSCs with pulse width modulation (PWM) operating at frequencies higher than the LCC system [6]. Therefore, VSC-HVDC transmission system became much more appropriate for renewable power transmission since it improved the disadvantages of the LCC based HVDC transmission systems [6-9].

Currently, VSC-HVDC schemes are widely applied in the renewable power networks such as long-distance offshore wind farm to the mainland onshore grid, which is owing to its advantages of reactive power compensation to weak $\mathrm{AC}$ systems and small size of the power conversion stations $[8,10]$. In 2014, the world first five-terminal VSCHVDC project, the $129 \mathrm{~km} \pm 200 \mathrm{kV}$ Zhoushan VSC-HVDC project, was put into service, with the total capacity (5 substations) of $1000 \mathrm{MW}$ [11]. The world's longest VSCHVDC light project is going to be commissioned in 2015, which is from Sweden to Lithuania $(450 \mathrm{~km})$ with the direct voltage $\pm 300 \mathrm{kV}$ and power capacity $700 \mathrm{MW}$ [12].

Additionally, control scheme also plays a significant role in the VSC-HVDC system as better control strategies not only improve the control speed but also reduce the power losses [13-15]. Consequently, a effective control design for the VSC-HVDC system greatly improves system performance and reliability $[4,15]$.

This paper reveals both the modeling and control of twoport VSC-HVDC transmission system using the platform of PSCAD/EMTDC. Section II presents the configuration of the VSC-HVDC model. Section III shows the control designs using phase \& magnitude control technique while the Section IV demonstrates control under d-q frame. Then, the steady state tests and dynamic load tests of VSC-HVDC under the above control strategies are illustrated in the Section V and Section VI respectively. Finally, Section VII presents the comparison between the phase \& magnitude control and control under d-q frame.

\section{The CONFIGURATION OF VSC-HVDC TRANSMISSION SYSTEM MODELING AND ITS COMPONENTS}

\section{A. The Configuration of VSC-HVDC Transmission System}

As demonstrated in Figure 1, the two-terminal VSCHVDC network consists of: two three-phase voltage source converters (the rectifier in the left side and inverter in the right side), AC sources, AC filters, phase reactors, DC-link capacitors and DC cables [6].

\section{B. Components}

Two converters are in this VSC-HVDC network. The left one is rectifier (converting $\mathrm{AC}$ to $\mathrm{DC}$ ) and the right one is inverter (converting DC to AC). Both of them are the twolevel VSC, which have three-phase, two-level and six-pulse bridges configuration. They consist of six valves, and each valve consists of an anti-parallel diode and an IGBT. Two 


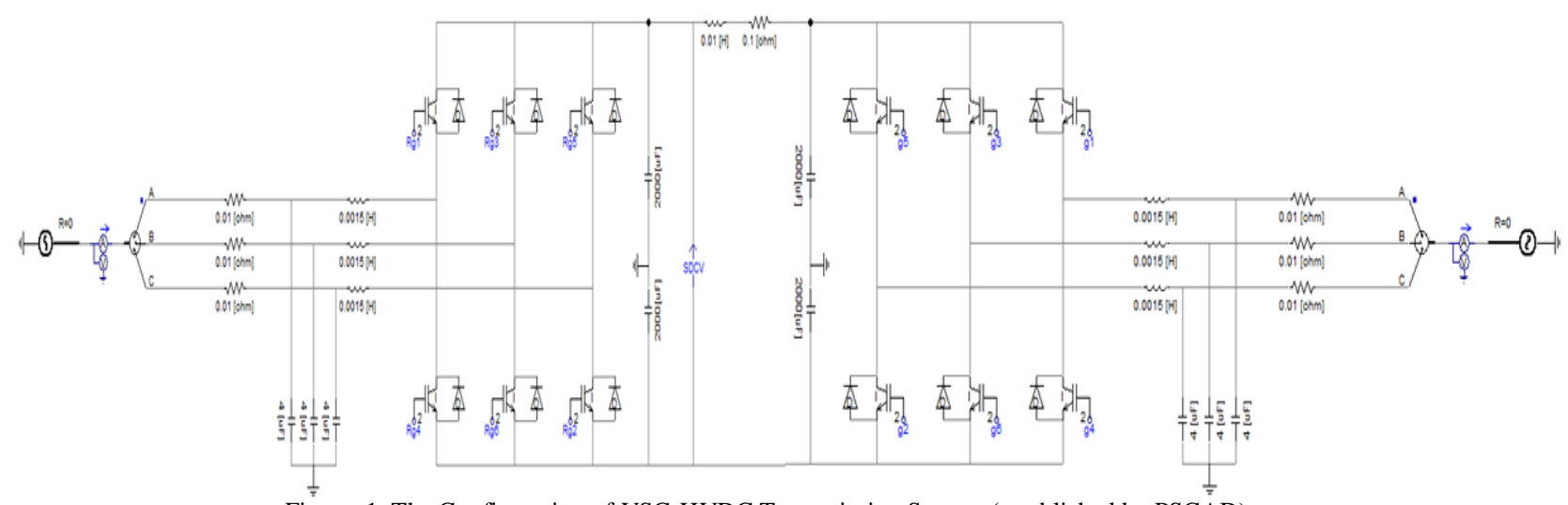

Figure 1. The Configuration of VSC-HVDC Transmission System (established by PSCAD)

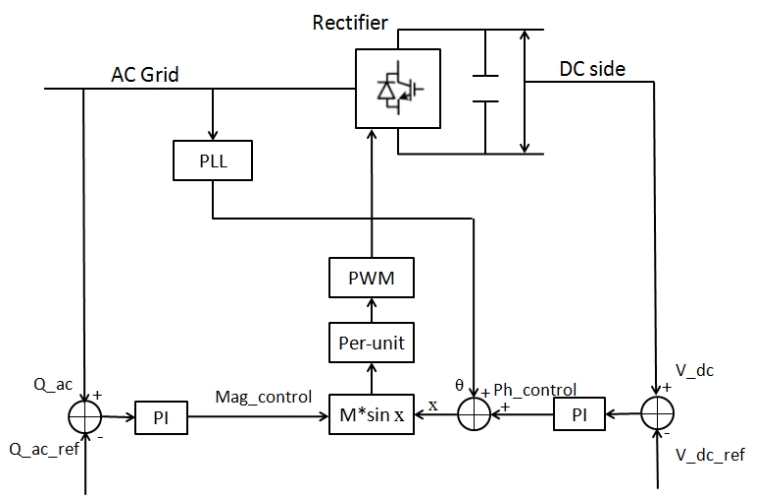

(a)

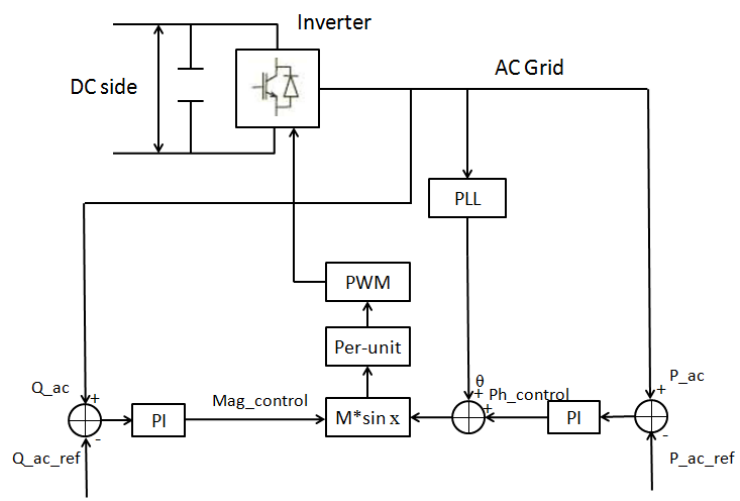

(b)

Figure 2. Control strategies under phase and magnitude control: (a) Rectifier side; (b) Inverter side

voltage levels can be operated by the two level six-pulse bridges, which are $+0.5 \mathrm{~V}_{\mathrm{dc}}$ and $-0.5 \mathrm{~V}_{\mathrm{dc}}$ (plus half and minus half of the DC voltage level).

Two three-phase AC sources are connected at the terminal of the AC networks. As the internal resistance in the sources is very small (for a strong system), the ideal threephase AC sources are selected, which is shown in Table 1. The base AC voltage and base complex power are in Table 2.

\begin{tabular}{|c|c|c|}
\hline $\mathbf{V}_{\text {ac-rms }}(\mathbf{k V})$ & Frequency $(\mathbf{H z})$ & Internal Resistance \\
\hline & & \\
\hline
\end{tabular}

TABLE II BASE VALUES OF VOLTAGE AND COMPLEX POWER

\begin{tabular}{|l|l|}
\hline $\mathbf{V}_{\text {base-rms }}(\mathbf{k V})$ & $\mathbf{S}_{\text {base }}$ (MVA) \\
\hline 100 & 100 \\
\hline
\end{tabular}

So,

$$
\begin{gathered}
Z_{\text {base }}=\frac{V_{\text {base }}^{2}}{S_{\text {base }}}=100 \Omega \\
L_{\text {base }}=\frac{Z_{\text {base }}}{2 \pi f}=0.318 \mathrm{H}
\end{gathered}
$$

Generally, the inductance of phase reactor is smaller than the half of the $\mathrm{L}_{\text {base, }}$ which should be smaller than $0.159 \mathrm{H}$.
So in this modeling, the inductance of phase reactor is set as: $\mathrm{L}_{\text {phase_reactor }}=0.0015 \mathrm{H}$.

The AC line resistance is much smaller than $\mathrm{Z}_{\text {base }}$. So in this modeling, the AC line resistance is set as: $R_{a c \_l i n e}=0.01$ $\Omega$.

$$
f_{c}=\frac{1}{2 \pi \sqrt{L C}}
$$

$\mathrm{f}_{\mathrm{c}}$ is the frequency of triangular wave in PWM processing. In this modeling, the capacitance of $\mathrm{AC}$ filter is set as: $\mathrm{C}_{\mathrm{ac} \_ \text {filter }}=4 \mathrm{mF}$. The DC-link capacitance is set as: $\mathrm{C}_{\mathrm{dc} \_ \text {link }}=$ $2000 \mathrm{uF}$ while the DC line impedance is very small. The DC cables value is set as: $R_{\text {dc_cable }}=0.1 \Omega$ and $L_{\text {dc_cable }}=0.01 \mathrm{H}$.

\section{Phase And Magnitude Control Design}

The phase and magnitude control strategy is based on the Equation (4):

$$
V_{R}=\frac{1}{2} V_{D C} M \sin (\omega t+\delta)+\text { harmonics }
$$

Figure 2 demonstrates the control strategies of rectifier and inverter under the phase and magnitude control. The control strategies are described step by step as follows. In the rectifier, the control parameters are $\mathrm{V}_{\mathrm{dc}}(\mathrm{SDCV})$ and $\mathrm{Q}_{\mathrm{ac}}$. Reference $V_{d c}$ is set at the DC side, and reference $Q_{a c}$ is set at 


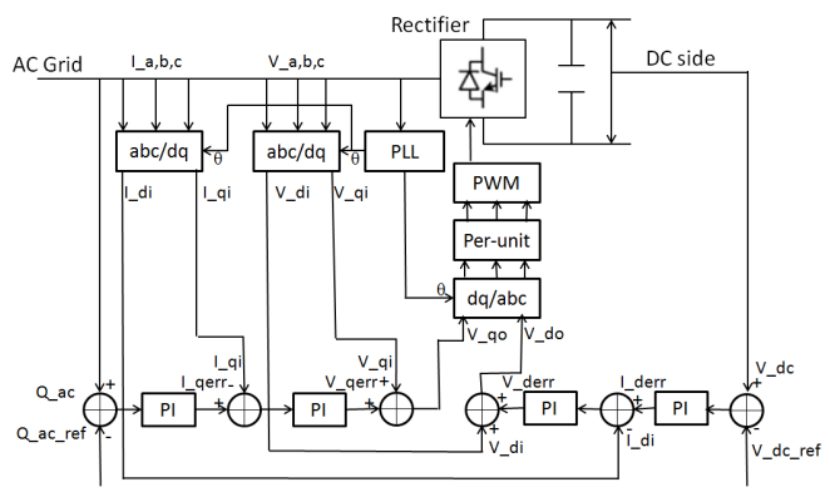

(a)

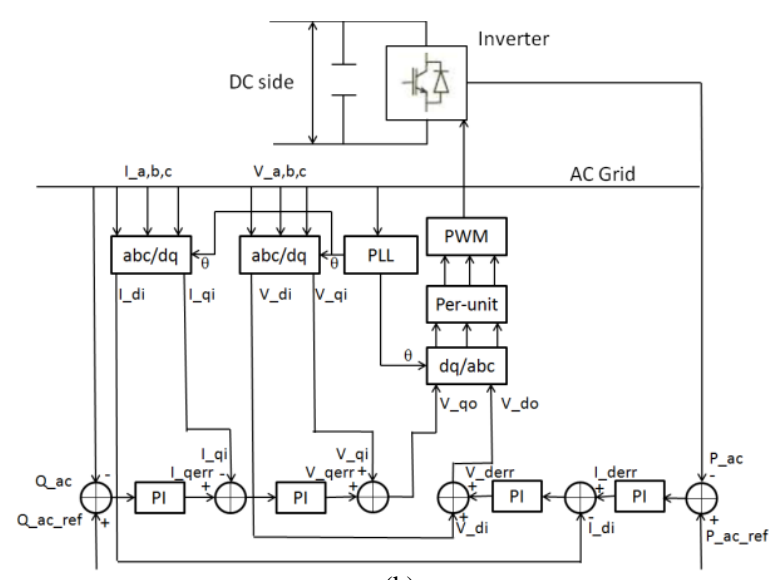

(b)

Figure 3. Control strategies with control under d-q frame: (a) Rectifier side; (b) Inverter side

the AC side. As shown in Figure 2 (a), the real $V_{d c}$ and real $\mathrm{Q}_{\mathrm{ac}}$ in the system are measured, and they are subtracted by reference $\mathrm{V}_{\mathrm{dc}}$ and reference $\mathrm{Q}_{\mathrm{ac}}$ respectively. Then, their differences pass through the PI controllers. Thus, the phase and magnitude control signal are obtained respectively. Afterwards, phase control signal is added together with phase shift signal from PLL (Phase Locked Loop), and it passes through the sinusoidal function and is multiplied by magnitude control signal to obtain the sinusoidal wave $\left(\mathrm{M}^{*} \sin \mathrm{x}\right)$. Then, sinusoidal wave is converted into per-unit value, and it is compared with a unit triangular wave. After that, the PWM signal is produced. PWM signals are sent into the IGBTs of the rectifier to operate the VSC-HVDC system. Then, the control loop continues to circulate.

Similarly, for the inverter side, the control parameters are $\mathrm{P}_{\mathrm{ac}}$ and $\mathrm{Q}_{\mathrm{ac}}$. Using the same control technique (phase and magnitude control) mentioned above, inverter control system is achieved, which is shown in Figure 2 (b).

\section{CONTROL DESIGN UNDER D-Q Frame}

As illustrated in Figure 3, the control strategies of rectifier and inverter are using control under $\mathrm{d}-\mathrm{q}$ frame. The control parameters are still $\mathrm{V}_{\mathrm{dc}}(\mathrm{SDCV})$ and $\mathrm{Q}_{\mathrm{ac}}$ in the rectifier side. Firstly, three-phase voltage signals are sent into the PLL to produce a phase shift signal. Then, this signal is added to 90 degrees (1.571 radians) to obtain a new phase shift signal called $\theta$. After that, the three-phase voltage signal and current signal are acquired in the AC network, and they are put together with $\theta$ into abc/dq transformation. The conversion equations are [14]:

$$
\begin{aligned}
& u_{c d}=u_{s d}+w L i_{q}-\left(R I_{d}+L \frac{d i_{d}}{d t}\right) \\
& u_{c q}=u_{s q}-w L i_{d}-\left(R I_{q}+L \frac{d i_{q}}{d t}\right)
\end{aligned}
$$

The $\mathrm{I}_{\mathrm{d}_{-} \mathrm{i}}, \mathrm{I}_{\mathrm{q}_{-} \mathrm{i}}, \mathrm{V}_{\mathrm{d}_{-} \mathrm{i}}$ and $\mathrm{V}_{\mathrm{q}_{\_} \mathrm{i}}$ are obtained at the output side of abc/dq transformation conversion. Reference $\mathrm{V}_{\mathrm{dc}}$ (SDCV) is set in the $\mathrm{DC}$ side, and reference $\mathrm{Q}_{\mathrm{ac}}$ is set in the $\mathrm{AC}$ side. As demonstrated in Figure 3 (a), the real $V_{d c}(S D C V)$ and real $\mathrm{Q}_{\mathrm{ac}}$ in the system are measured, and they are subtracted by reference $V_{d c}$ and reference $Q_{a c}$ respectively. Then, their differences pass through the PI controllers. After that, the $\mathrm{I}_{\mathrm{d} \_\mathrm{i} \text { error }}$ and $\mathrm{I}_{\mathrm{q} \_ \text {i_error }}$ are obtained respectively. Consequently, the $I_{d_{-} i \text { error }}$ is subtracted by $I_{d_{-} i}$ and $I_{q_{-} i \text { error }}$ is subtracted by $\mathrm{I}_{\mathrm{q}_{\mathrm{i}} \mathrm{i}}$. Then, their differences pass through the PI controllers. Then, the $\mathrm{V}_{\mathrm{d} \_ \text {error }}$ and $\mathrm{V}_{\mathrm{q} \_ \text {error }}$ signal are obtained respectively. As presented in Figure 3 (a), $\mathrm{V}_{\mathrm{d}_{\_} \mathrm{i}}$ and $\mathrm{V}_{\mathrm{d} \_ \text {error }}$ are added together to obtain $\mathrm{V}_{\mathrm{d}_{\_} \mathrm{o}}$. Similarly, $\mathrm{V}_{\mathrm{q}_{-} \mathrm{i}}$ and $\mathrm{V}_{\mathrm{q} \_ \text {error }}$ are added together to obtain $\mathrm{V}_{\mathrm{q}_{-} \mathrm{o}}$. Afterwards, the phase shift signal $\theta$ together with the $\mathrm{V}_{\mathrm{d}_{-} \mathrm{o}}$ and $\mathrm{V}_{\mathrm{q}_{\_} \mathrm{o}}$ are put into the $\mathrm{dq} / \mathrm{abc}$ reverse transformation. Finally, the three-phase voltage signals of $\mathrm{V}_{\mathrm{a} \_\mathrm{o}}, \mathrm{V}_{\mathrm{b} \_\mathrm{o}}$ and $\mathrm{V}_{\mathrm{c} \_\mathrm{o}}$ are obtained.

The three-phase $\mathrm{V}_{\mathrm{a} \_\mathrm{o}}, \mathrm{V}_{\mathrm{b}_{-} \mathrm{o}}$ and $\mathrm{V}_{\mathrm{c}_{\text {_o }}}$ are made in per-unit value and then converted into the logical PWM signals, which are used to operate the IGBTs in rectifier. The same control technology is applied in inverter side. The only difference from rectifier is that the control parameters are $\mathrm{P}_{\mathrm{ac}}$ and $\mathrm{Q}_{\mathrm{ac}}$ at the inverter side.

\section{Steady State Tests}

This section presents the steady state tests of the VSCHVDC system using phase \& magnitude control and control under d-q frame respectively.

\section{A. Tests Using Phase and Magnitude Control}

At the rectifier side, as presented in Figure 4 (a), from $\mathrm{t}=0 \mathrm{~s}$ to $\mathrm{t}=1 \mathrm{~s}$, there is a small overshoot in DC voltage. After $\mathrm{t}=1.5 \mathrm{~s}$, the $\mathrm{DC}$ voltage is controlled approximately at reference value of $500 \mathrm{kV}$. Meanwhile, the $\mathrm{AC}$ reactive power is successfully controlled to maintain around $0 \mathrm{MVar}$ (reference value) from $\mathrm{t}=2.5 \mathrm{~s}$ to the end of the simulation. At the inverter side, as shown in Figure 4 (b), from $t=1.8 \mathrm{~s}$ onwards, AC active power is controlled around at the 


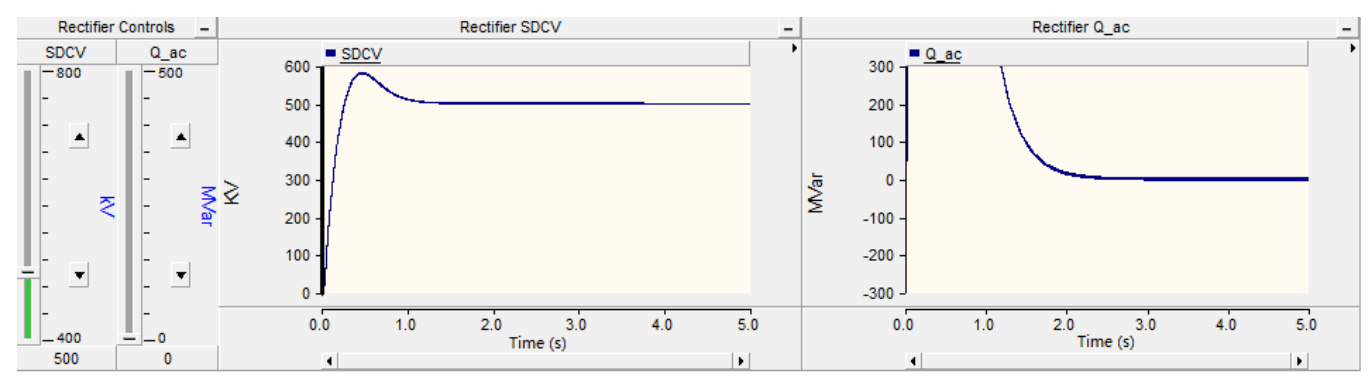

(a)

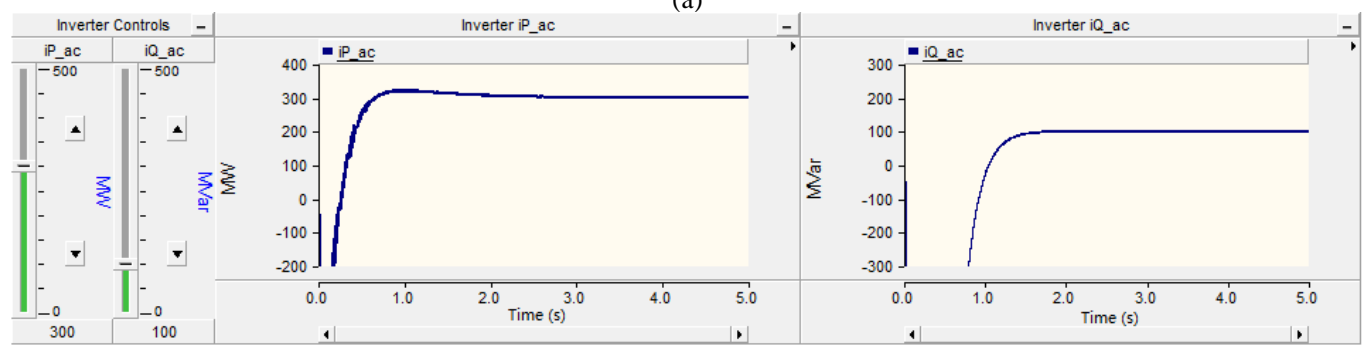

(b)

Figure 4. Steady state test with phase and magnitude control: (a) DC voltage and AC reactive power on the rectifier side; (b) AC active power and AC reactive power on the inverter side
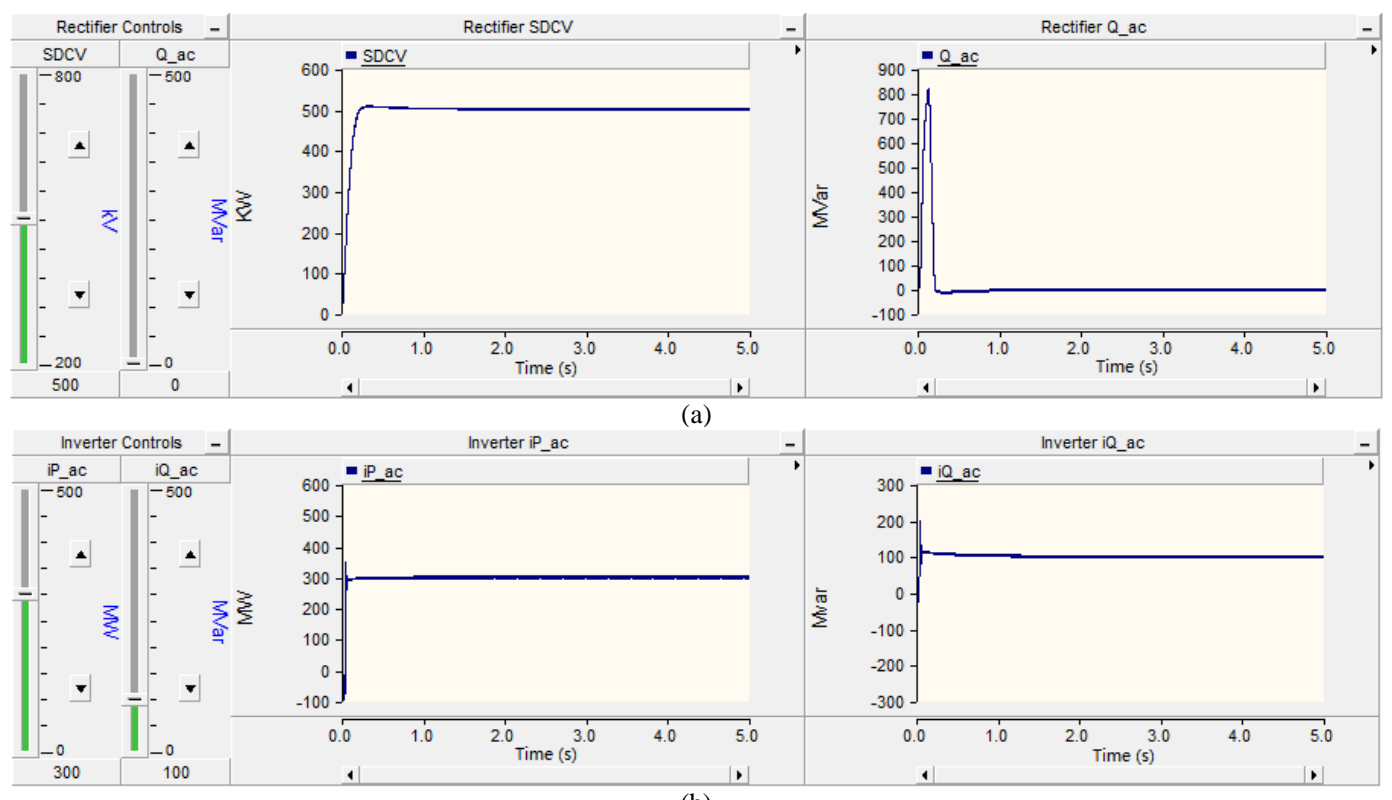

(b)

Figure 5. Steady state test with control under d-q frame: (a) DC voltage and AC reactive power on the rectifier side; (b) AC active power and AC reactive power on the inverter side 


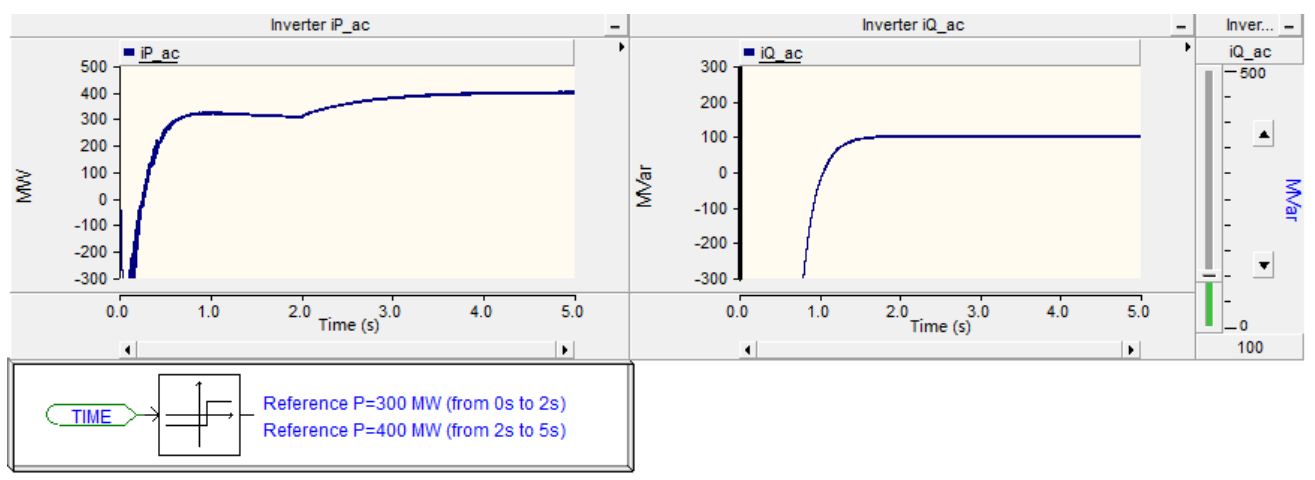

Figure 6. Dynamic load test with phase and magnitude control

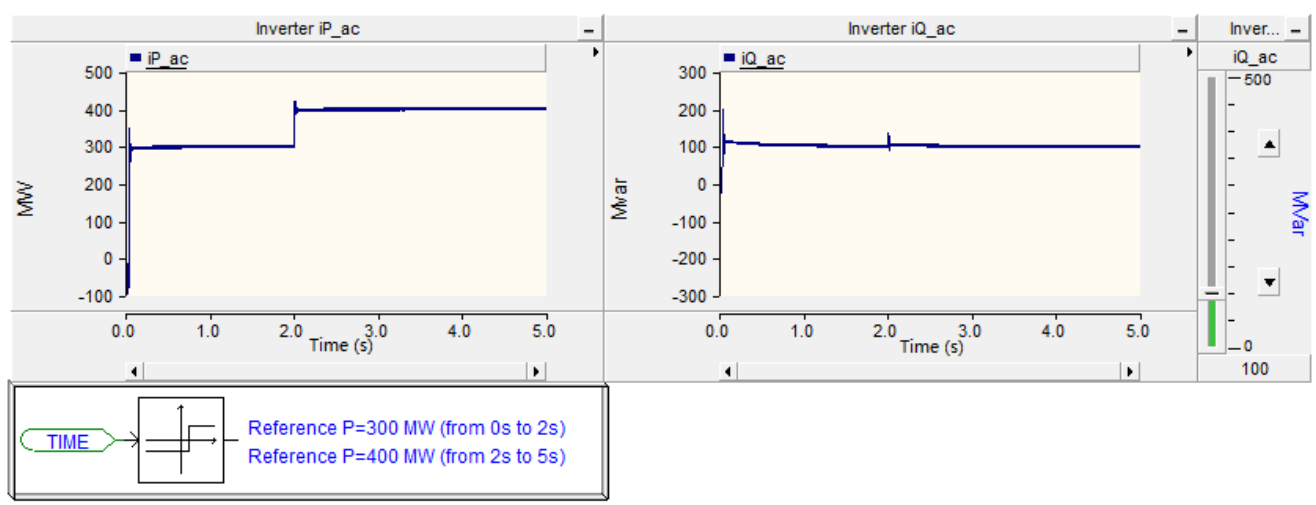

Figure 7. Dynamic load test with control under d-q frame

reference value of $300 \mathrm{MW}$. At the same time, from $\mathrm{t}=0 \mathrm{~s}$ to $\mathrm{t}=1.5 \mathrm{~s}$, there is a huge undershoot in $\mathrm{AC}$ reactive power. But $\mathrm{AC}$ reactive power is controlled to maintain approximately 100 MVar (reference value) after $\mathrm{t}=1.8 \mathrm{~s}$ to the end of the simulation.

\section{B. Tests Using Control under D-Q Frame}

At the rectifier side, as illustrated in Figure 4 (b), the DC voltage is controlled nicely at the reference value of $500 \mathrm{kV}$ during the whole simulation. Meanwhile, from $\mathrm{t}=0 \mathrm{~s}$ to $\mathrm{t}=0.2$ $\mathrm{s}$, there is an overshoot in AC reactive power. After that, the $\mathrm{AC}$ reactive power is controlled to maintain around $0 \mathrm{MVar}$ (reference value).

At the inverter side, as shown in Figure 4 (b), both the $\mathrm{AC}$ active power and $\mathrm{AC}$ reactive power are controlled shortly to maintain their reference values $(\mathrm{P}=300 \mathrm{MW}$ and $\mathrm{Q}=100 \mathrm{MVar}$ ) respectively during the whole simulation.

\section{DYNAMIC LOAD TESTS}

The following paragraphs reveal the dynamic load test of the VSC-HVDC system using phase \& magnitude control and control under d-q frame respectively.

A. Tests Using Phase and Magnitude Control

In order to achieve the dynamic load test on the inverter side, the first reference $\mathrm{AC}$ active power $\left(\mathrm{P}_{\mathrm{ac}}\right)$ is set at 300 MW from $t=0 \mathrm{~s}$ to $\mathrm{t}=2 \mathrm{~s}$, and the second reference is set at
$400 \mathrm{MW}$ from $\mathrm{t}=2 \mathrm{~s}$ to $\mathrm{t}=5 \mathrm{~s}$. As demonstrated in Figure 6, from $\mathrm{t}=1.8 \mathrm{~s}$ onwards, the $\mathrm{AC}$ active power is controlled around at the first reference value of $300 \mathrm{MW}$. As reference value of $\mathrm{P}_{\mathrm{ac}}$ is changed instantly from the $300 \mathrm{MW}$ to 400 $\mathrm{MW}$ at $\mathrm{t}=2 \mathrm{~s}$, the AC active power increases gradually from $300 \mathrm{MW}$ to $400 \mathrm{MW}$ by the control of PI controller during the period from $\mathrm{t}=2 \mathrm{~s}$ to $\mathrm{t}=4.5 \mathrm{~s}$. After $\mathrm{t}=4.5 \mathrm{~s}$, it maintains approximately $400 \mathrm{MW}$ (second reference value) in the rest of the simulation. The AC reactive power is stably controlled at the reference value of $100 \mathrm{MVar}$ from $\mathrm{t}=1.8 \mathrm{~s}$ to $\mathrm{t}=5 \mathrm{~s}$.

\section{B. Tests Using Control under D-Q frame}

With the same setting of the reference AC active power on the inverter side $(300 \mathrm{MW}$ from $\mathrm{t}=0 \mathrm{~s}$ to $\mathrm{t}=2 \mathrm{~s}$, and 400 MW from $t=2 s$ to $t=5 s$ ), the dynamic test is using the control under d-q frame. As demonstrated in Figure 7. The $\mathrm{AC}$ active power have small undershoots at the beginning, but they are controlled shortly and maintain the reference values $(\mathrm{P}=300 \mathrm{MW})$ to $\mathrm{t}=2 \mathrm{~s}$. Then, it instantaneously goes up to $400 \mathrm{MW}$ (second reference value) and maintains this value to the end of the simulation.

\section{COMPARISON BeTweEn Two Control Designs}

The foregoing figures and descriptions of the steady state tests and dynamic load tests demonstrate that the VSCHVDC transmission system operates in the good condition 
using the two control methods respectively. However, there are still some strength and weakness in these two control methods.

For phase and magnitude control, $\mathrm{P}$ and $\mathrm{Q}$ still affect each other because phase and magnitude control does not make the P and Q fully decoupled, which results it difficult to control the system efficiently, especially in the dynamic load condition with the slow transition between two reference voltages. But one advantage of phase and magnitude control is that the control design is relatively easy.

The biggest advantage of control under $\mathrm{d}-\mathrm{q}$ frame is the fully decoupled characteristic, so the $\mathrm{P}$ and $\mathrm{Q}$ can be completely independently controlled. Compared with phase and magnitude control, control under $\mathrm{d}-\mathrm{q}$ frame is much faster, which can be seen from Figure 5 and Figure 7 However, the design of control under $\mathrm{d}-\mathrm{q}$ frame is relatively complex.

\section{CONCLUSION}

The modeling and control of VSC-HVDC transmission system have been achieved using the software of PSCAD/EMTDC. The phase and magnitude control design as well as the control design under $\mathrm{d}-\mathrm{q}$ frame have been completed. As simulation results shown, the VSCHVDC system has been operated successfully by using the two control methods respectively. The biggest advantage of control under $\mathrm{d}-\mathrm{q}$ frame is the fully decoupled characteristic, so the $\mathrm{P}$ and $\mathrm{Q}$ can be completely independently controlled. Therefore, control under $\mathrm{d}-\mathrm{q}$ frame is faster and more stable than phase and magnitude control.

\section{ACKNOWLEDGMENT}

The modeling of VSC-HVDC transmission system was achieved with the help of the Department of Electrical and Electronic Engineering (EEE), School of Engineering, Cardiff University. I am especially grateful to the all the members of staff in the EEE Department.

\section{REFERENCES}

[1] D. Van Hertem and M. Ghandhari, "Multi-terminal VSC HVDC for the European supergrid: Obstacles," Renewable and Sustainable Energy Reviews, vol. 14, pp. 3156-3163, 2010.

[2] L. Weimers, "HVDC light: a new technology for a better environment," Power Engineering Review, IEEE, vol. 18, pp. 1920, 1998.

[3] J. M. Carrasco, L. G. Franquelo, J. T. Bialasiewicz, E. Galván, R. P. Guisado, M. A. Prats, et al., "Power-electronic systems for the grid integration of renewable energy sources: A survey," Industrial Electronics, IEEE Transactions on, vol. 53, pp. 1002-1016, 2006.

[4] D. Povh, P. Thepparat, and D. Westermann, "Analysis of innovative HVDC control," in PowerTech, 2009 IEEE Bucharest, 2009, pp. 1-7.

[5] W. Long and S. Nilsson, "HVDC transmission: yesterday and today," Power and Energy Magazine, IEEE, vol. 5, pp. 22-31, 2007.

[6] N. Flourentzou, V. G. Agelidis, and G. D. Demetriades, "VSCbased HVDC power transmission systems: an overview," Power Electronics, IEEE Transactions on, vol. 24, pp. 592-602, 2009.
[7] J. Liang, "Control of multi-terminal VSC-HVDC transmission for offshore wind power," in 2009 13th European Conference on Power Electronics and Applications, 2009, pp. 1-10.

[8] J. Liang, T. Jing, O. Gomis-Bellmunt, J. Ekanayake, and N. Jenkins, "Operation and control of multiterminal HVDC transmission for offshore wind farms," Power Delivery, IEEE Transactions on, vol. 26, pp. 2596-2604, 2011.

[9] S. Wang, J. Liang, and J. Ekanayake, "Optimised topology design and comparison for offshore transmission," in Universities Power Engineering Conference (UPEC), 2012 47th International, 2012 pp. 1-6.

[10] A. Moawwad, M. S. El Moursi, W. Xiao, and J. Kirtley, "Novel Configuration and Transient Management Control Strategy for VSC-HVDC," 2014.

[11] N. E. C. Ltd, "World First Five-Terminal VSC-HVDC Transmission Project," 2014.

[12] ABB, "HVDC Light ${ }^{\circledR}$ - The Original VSC Technology Reference List," 2013

[13] A. Moawwad, M. El Moursi, and W. Xiao, "A Novel Transient Control Strategy for VSC-HVDC Connecting Offshore Wind Power Plant."

[14] J. Beerten, S. Cole, and R. Belmans, "Modeling of Multi-Terminal VSC HVDC Systems With Distributed DC Voltage Control," 2012.

[15] S. Li, T. A. Haskew, and L. Xu, "Control of HVDC light system using conventional and direct current vector control approaches," Power Electronics, IEEE Transactions on, vol. 25, pp. 3106-3118, 2010. 